\title{
Striving for Global Representation
}

\author{
Peter Black, Editor-in-Chief $\bowtie$
}

Soc Int Urol J.2021;2(2):77-78

DOI: 10.48083/VZOD4051

The third issue of the Société Internationale d'Urologie Journal hits many of the highlights of what we are trying to achieve with our fledgling journal. The truly global character and special flavor of the SIUJ are coming to the fore. This in turn is reflective of the mission of the larger SIU "to enable urologists in all nations, through international cooperation in education and research, to apply the highest standards of urological care to their patients." We are a society of all urologists in all countries in the world, not limited by specific geographical or subspecialty boundaries. It is therefore critical that the pages of our journal represent broad global reach.

The most obvious example of this is Christian Agbo's contribution to "Urology Around the World," which attests to the trials and tribulations of stone management in Nasarawa State in North Central Nigeria[1]. There is a clear sentiment in this article that Dr Agbo would like to be offering his patients more, as he strives to improve access to advanced technologies in a resource-poor setting. At the same time, those of us in resource-rich environments may contemplate our excesses in comparison to the limitations in Nigeria, and be reminded of our duty to use our resources responsibly, and to consider the environmental impact and sustainability of our practices. We also need to be thinking about how we can develop clinical practice guidelines that can be applied beyond the borders of the wealthiest countries, as outlined in the last issue of the SIUJ by German Patino et al.[2].

The collaborative work of Joyce Baard et al. exemplifies global collaboration in research through the SIU network of urologists[3]. We are particularly proud to publish this first project of uCARE, the research arm of the SIU. The paper reports results derived from a prospective registry of ureteral stent insertion after ureteroscopy. The registry captured patients from 50 centers in many different countries, ranging from
Saudi Arabia to South Africa, and from Iran to Malaysia and Indonesia. The project reinforced connections between various national urological societies and the SIU. This paper reflects the power of global research cooperation and provides a uniquely international perspective on this common urologic procedure. It fulfills the SIU's objective to foster cooperation between urologists from all parts of the world despite differences in material conditions, professional concerns, and political views.

Ibrahem Ismail Samaha et al. report the results of a prospective randomized trial comparing a traditional transvesical approach for vesicovaginal fistula repair to a novel, potentially less invasive extravesical approach[4]. This type of surgery is particularly important in many regions of the world that make up key constituencies of the SIU, so we are especially proud that the first randomized controlled trial to be published in the SIUJ is on such a pertinent topic in global surgery.

Education is front and center in the SIU mission, and it is therefore only apt that Jessica DeLong and Ramón Virasaro describe in the pages of the SIUJ a curriculum that has been established for genitourinary reconstructive surgery in the Dominican Republic[5]. With buy-in from all major stakeholders, this curriculum has been launched successfully, and the first trainees have completed the program. This project has implications for global surgical training beyond the Caribbean, as it provides a model that is transferable to other health care settings.

As we continue to build the foundation of a new journal representing 10000 SIU members from over 130 countries worldwide, we strive to provide a vehicle for optimal communication of scientific information. Our global reach helps distinguish us in the crowded field of urologic journals. 


\section{References}

1. Agbo C. Open Surgery for Urinary Stones in a Resource Poor Setting: A Look at Dalhatu Araf Specialist Hospital, Lafia, Nigeria. Soc Int Urol J.2021;2(2):79-81.DOl: 10.48083/KF0Z6048.

2. Patino G, Ndoye M, Thomas HS, Cohen AJ, Mmonu NA, Chu CE, et al. Use of urology-based clinical practice guidelines in international settings. Soc Int Urol J.2021;2(1):10-17. DOI: 10.48083/OVXE4949.

3. Dasgupta R, Ong TA, Lim J, Rajandram R, Gao X, Hakim L, et al. A global perspective of stenting after ureteroscopy: an observational multicenter cohort study. Soc Int Urol J.2021;2(2):96-105.DOI: 10.48083/HRLS8587.
4. Samaha I, Taha KM, Elbabouly I, Ali M. Novel Extravesical Versus Transvesical Technique for Abdominal Repair of Vesicovaginal Fistula. Soc Int Urol J.2021;2(2):113-119.DOI: 10.48083/TVYU2515.

5. DeLong J, Virasaro R. Genitourinary reconstructive surgery curriculum and postgraduate training program development in the Caribbean. Soc Int Urol J.2021;2(2):106-112.DOI: 10.48083/ RORD8326. 